\title{
Pocket computers: a new aid to nutritional support
}

\author{
C M COLLEY, A FLECK, J P HOWARD
}

\begin{abstract}
A program has been written to run on a pocket computer (Sharp PC-1500) that can be used at the bedside to predict the nutritional requirements of patients with a wide range of clinical conditions. The predictions of the program showed good correlation with measured values for energy and nitrogen requirements. The program was used, with good results, in the management of over 100 patients needing nutritional support.

The calculation of nutritional requirements for each patient individually facilitates more appropriate treatment and may also produce financial savings when compared with administration of a standard feeding regimen to all patients.
\end{abstract}

\section{Introduction}

Excessive intake of energy in patients fed parenterally may produce undesirable complications, such as hepatomegaly and liver dysfunction ${ }^{1}$ and hyperglycaemia leading to osmotic diuresis. ${ }^{2}$ In acutely ill patients an excess input of energy may result in increased production of carbon dioxide and risk of respiratory acidosis $^{34}$ or obesity with concomitant disadvantages during early mobilisation. Underfeeding of patients who are nutritionally depleted is also undesirable. The daily intakes of food energy recommended by the Department of Health and Social Security are for healthy, active people $e^{5}$ and are therefore inappropriate for sick patients in hospital. Moreover, they are given as averages and make no attempt to distinguish between persons. Recent evidence suggests that the energy requirements of acutely ill patients are much less than previously proposed.$^{67}$ An appropriate, individually calculated amount of energy is therefore likely to be beneficial to the patient and to produce a decrease in the cost of feeding, as is an appropriate amount of nitrogen.

The objective of a clinical nutrition service must be to provide the correct amount of nutrients to suit the changing condition of the patient. The ideal would be to measure the metabolic rates of all the patients receiving nutritional support, but in most hospitals this is impossible. The energy requirement of each patient receiving nutritional support must therefore be estimated. To facilitate this we have devised a computer program that runs on a pocket computer, which calculates a patient's energy requirements based on data from published reports. In addition, requirements of nitrogen, water, sodium, and potassium are estimated. The dimensions of the computer (Sharp PC-1500) when it is not attached to the printer are $19.5 \times 8.5 \times 2.5 \mathrm{~cm}$, and it can thus be easily carried in a doctor's pocket to the patient's bedside, where all the relevant data should be available.

Although a few computer programs are available that perform similar calculations, these are generally written for large computers that are not portable. A programmable calculator system for estimating nutritional requirements has been reported previously. ${ }^{8}$ In this it was necessary to enter a "catabolic factor," which had to be decided on by the user. Advancing technology has made it

\footnotetext{
Departments of Chemical Pathology and Nutrition and Dietetics, Charing Cross Hospital and Medical School, London W6 8RF

C M COLLEY, MB, PHD, lecturer in chemical pathology

A FLECK, FRCPATH, FRSED, professor of chemical pathology

J P HOWARD, SRD, district dietitian

Correspondence to: Dr C M Colley, Department of Clinical Chemistry, Royal Berkshire Hospital, Reading, Berkshire RGI SAN.
}

possible to contain a larger, more versatile program within a smaller physical size of computer. In our program allowances for disease and trauma are calculated by the computer. In addition, the display can give messages to prompt the input of data without the user's having to remember the correct order of entry of the data. The program also checks for the entry of inappropriate data.

The computer may also be used for non-programmed calculations in a manner similar to a pocket calculator. A further version of the program has been written to run on the Sharp PC1251 , which is smaller $(13.5 \times 7.0 \times 0.9 \mathrm{~cm})$ and cheaper.

\section{Methods and subjects \\ COMPUTER AND COMPUTER PROGRAM}

The program is written in BASIC on a Sharp PC-1500 pocket computer (Sharp Electronics, UK) (fig 1). The use of this widely known computer language means that modifications to the program may easily be made to suit local requirements. The computer can be used alone, with the results read from the liquid-crystal display, or attached to its printer to give printed output. The program is retained in the memory even when the computer is switched off.

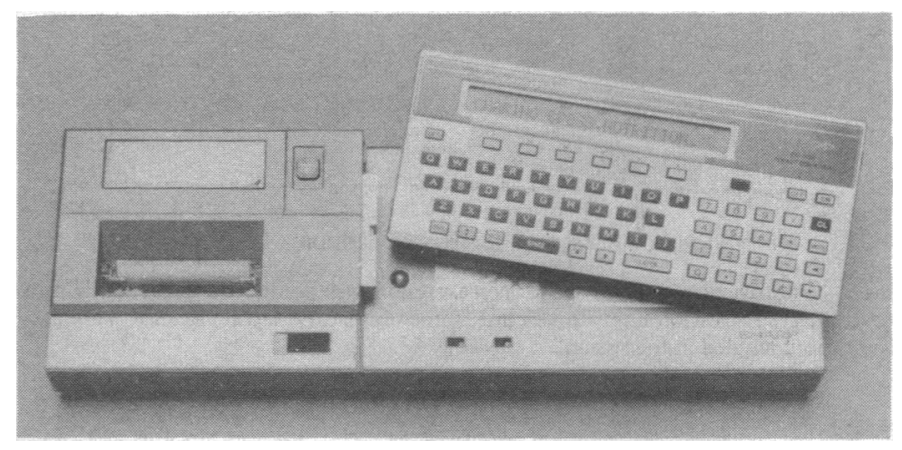

FIG 1-Sharp PC-1500 microcomputer resting on optional printer and cassette interface.

\begin{tabular}{lc} 
TABLE I-Modifications to basal metabolic rate used \\
in computer program according to state of patient \\
\hline & \\
\hline & Modification (\%) \\
\hline Mobility: & \\
On ventilator & -15 \\
Awake in bed & +10 \\
In chair & +20 \\
Up and about & +30 \\
Trauma: & +10 \\
<7 days after operation & +10 \\
Single fracture & +25 \\
Multiple fractures & +10 \\
Sepsis: & +20 \\
Mild & +40 \\
Moderate & +60 \\
Severe & \\
Severe with respiratory failure & \\
\hline
\end{tabular}

The initial variables to be entered are the patient's age, sex, weight, and height. From these an estimated basal metabolic rate is calculated using the data of Robertson and Reid" and Dubois and Dubois. ${ }^{10}$ Modifications are then made to this basal metabolic rate to allow for various factors including fever $\left(10 \%\right.$ increase in energy for each ${ }^{\circ} \mathrm{C}$ above $\left.37^{\circ} \mathrm{C}\right)$ and the degree of mobility of the patient, trauma, and sepsis (table I). ${ }^{112}$ The increase due to burns is calculated from the percentage of the surface area affected and the 
temperature at which the patient is nursed. ${ }^{12}$ When weight gain is required an addition of $1.3 \mathrm{MJ}(300 \mathrm{kcal}) /$ day is made, to allow for a gain of $500-600$ $\mathrm{g}$ lean body mass/week. ${ }^{13}$ The final result is increased by $10 \%$ to allow for the specific dynamic action of feeding.

The nitrogen requirement is calculated in proportion to the energy requirement and depends on the degree of trauma. In patients who are solely undernourished the ratio used is $1 \mathrm{~g}$ nitrogen $/ 0.8 \mathrm{MJ}(200 \mathrm{kcal})$ rising with increasing trauma to $1 \mathrm{~g}$ nitrogen $/ 0.4 \mathrm{MJ}(100 \mathrm{kcal})$ in patients with severe sepsis. ${ }^{14}$ The program includes the facility to calculate the production of urea nitrogen in patients with renal failure, using serum urea concentrations and body weights. ${ }^{15}$

The program also calculates estimated requirements of water, sodium, and potassium. Water requirement is taken as $1 \mathrm{ml} / 4 \cdot 18 \mathrm{~kJ}(1 \mathrm{kcal})$ in normal patients, ${ }^{16}$ rising to $1.5 \mathrm{ml} / 4.18 \mathrm{~kJ}(1 \mathrm{kcal})$ in patients with severe trauma or sepsis. To the resultant volume are added any losses from fistulas and any other abnormal losses of fluid such as diarrhoea or vomiting. Sodium requirement is taken to be $1 \mathrm{mmol}(\mathrm{mEq}) / \mathrm{kg}$ body weight plus losses from fistulas ${ }^{16}$ and potassium as $6 \mathrm{mmol}(\mathrm{mEq}) / \mathrm{g}$ nitrogen plus losses

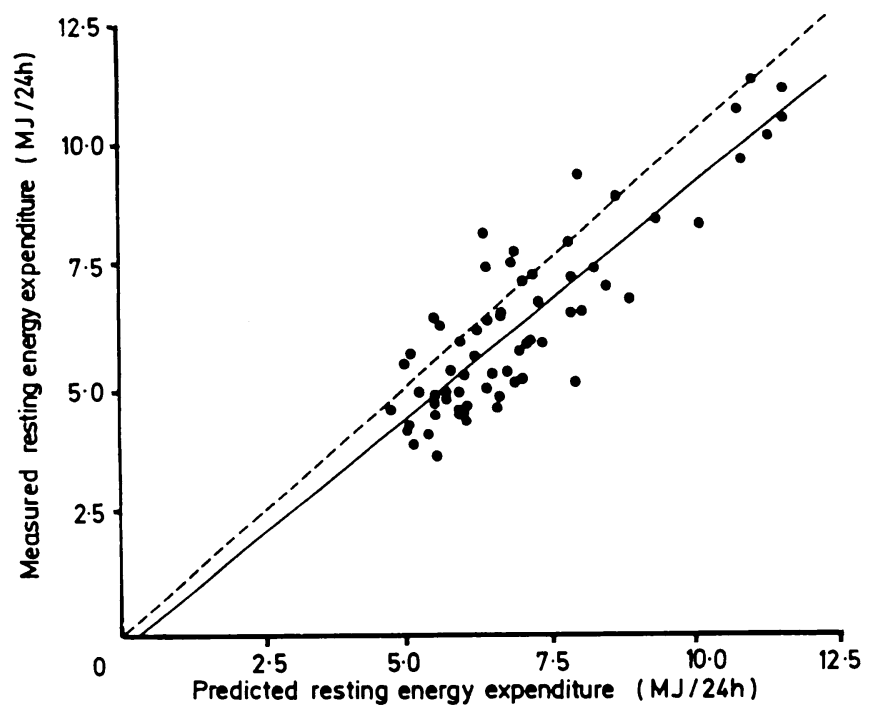

FIG 2-Comparison of measured nitrogen excretion with predicted values. Solid line is least squares regression line. Broken line is line of identity. Open circles $(O)$ are data points not included in regression.

from fistulas. The losses of sodium and potassium from fistulas are calculated by multiplying the volume lost by the concentrations of sodium and potassium in the various intestinal fluids. ${ }^{17}$

\section{MEASUREMENT OF ENERGY EXPENDITURE AND NITROGEN EXCRETION}

Resting expenditure of energy was measured by indirect calorimetry. At this hospital we used an instrument constructed in the department of respiratory medicine in the medical school. This comprised a ParkinsonCowan CD4 dry gas meter to measure inspired volume, a Taylor-Servomex paramagnetic oxygen meter, and a Hartmann and Braun URAS 2 infrared carbon dioxide meter to measure gas concentrations in the inspired and expired air. Some measurements were provided by the Medical Research Council, Trauma Unit, Hope Hospital, Salford; these were carried out with a Beckman metabolic measurement cart.

Nitrogen excretion was measured on $1 \mathrm{ml}$ aliquots of urine taken from complete 24 hour urine collections using a Kjeltech semimicro Kjeldahl apparatus (Tecator, Bristol). The mean of the values obtained for three days after the computer estimate was taken.

\section{SUBJECTS STUDIED}

The energy expenditures of 66 patients and fit volunteers were measured. The clinical condition of the patients ranged from uncomplicated malnutrition, through various degrees of trauma, to necrotising pancreatitis with respiratory and renal failure.

\section{Results}

Of the 66 patients, three $(4 \cdot 5 \%)$ had measured resting energy expenditures below $4.18 \mathrm{MJ}(1000 \mathrm{kcal}) /$ day, $60(91 \%)$ between $4 \cdot 18$ and $10.5 \mathrm{MJ}$ $(1000$ and $2500 \mathrm{kcal}) /$ day, and three $(4.5 \%)$ greater than $10.5 \mathrm{MJ}$ $(2500 \mathrm{kcal}) /$ day. The least squares regression line of measured resting energy expenditure on predicted resting energy expenditure had a gradient of 0.93 with a correlation coefficient of 0.83 (fig 2). The only patients found to have resting energy expenditures greater than $10.5 \mathrm{MJ}(2500 \mathrm{kcal}) /$ day were those with severe abdominal sepsis, such as necrotising pancreatitis, and the highest value measured was $11.3 \mathrm{MJ}(2700 \mathrm{kcal}) / \mathrm{day}$. The comparison made above took into account the effects of all factors except mobility. It was not possible, using the available equipment, to measure the energy expenditure of patients when mobile, but over $90 \%$ of the patients were bedbound when studied. Table II shows predicted and measured resting energy expenditures and recommended daily intakes for seven patients.

TABLE II-Comparison of predicted and measured resting energy expenditure with recommended daily intake

\begin{tabular}{|c|c|c|c|c|c|}
\hline $\begin{array}{l}\text { Sex } \\
\text { and } \\
\text { age } \\
\text { (years) }\end{array}$ & $\begin{array}{c}\text { Weight } \\
(\mathbf{k g})\end{array}$ & Condition & $\begin{array}{c}\text { Recommended } \\
\text { daily } \\
\text { intake } \\
(\mathrm{MJ})\end{array}$ & $\begin{array}{l}\text { Predicted } \\
\text { resting } \\
\text { energy } \\
\text { expenditure } \\
\text { (MJ) }\end{array}$ & $\begin{array}{l}\text { Measured } \\
\text { resting } \\
\text { energy } \\
\text { expenditure } \\
\text { (MJ) }\end{array}$ \\
\hline $\begin{array}{ll}F & 20 \\
F & 57 \\
F & 60 \\
M & 18 \\
M & 52 \\
M & 55 \\
M & 56\end{array}$ & $\begin{array}{l}47 \cdot 5 \\
54 \cdot 7 \\
55 \cdot 8 \\
35 \cdot 2 \\
98 \cdot 7 \\
72 \cdot 3 \\
69 \cdot 0\end{array}$ & $\begin{array}{l}\text { Hydatidiform mole } \\
\text { Carcinoma } \\
\text { Guillain-Barré syndrome } \\
\text { Cystic fibrosis } \\
\text { Abdominal sepsis } \\
\text { Low grade sepsis } \\
\text { Necrotising pancreatitis }\end{array}$ & $\begin{array}{r}9.0 \\
7.9 \\
7.9 \\
10 \cdot 5 \\
10.0 \\
10 \cdot 0 \\
10.0\end{array}$ & $\begin{array}{r}6 \cdot 0 \\
6 \cdot 2 \\
4 \cdot 8 \\
5 \cdot 1 \\
11 \cdot 8 \\
8 \cdot 0 \\
11 \cdot 0\end{array}$ & $\begin{array}{r}5.9 \\
6 \cdot 5 \\
4 \cdot 6 \\
5.5 \\
11 \cdot 1 \\
8.0 \\
11 \cdot 3\end{array}$ \\
\hline
\end{tabular}

Conversion: SI to traditional units-Energy: $1 \mathrm{MJ} \approx 239 \mathrm{kcal}$.

There was similarly good correlation between the predicted nitrogen requirement and measured urinary nitrogen excretion, with a slope of 0.97 and a correlation coefficient of 0.96 (fig 3). Data from six patients were excluded from the regression: the two data points above the regression line were from patients receiving chemotherapy for tumours and the four below the line were from patients with hepatorenal failure.

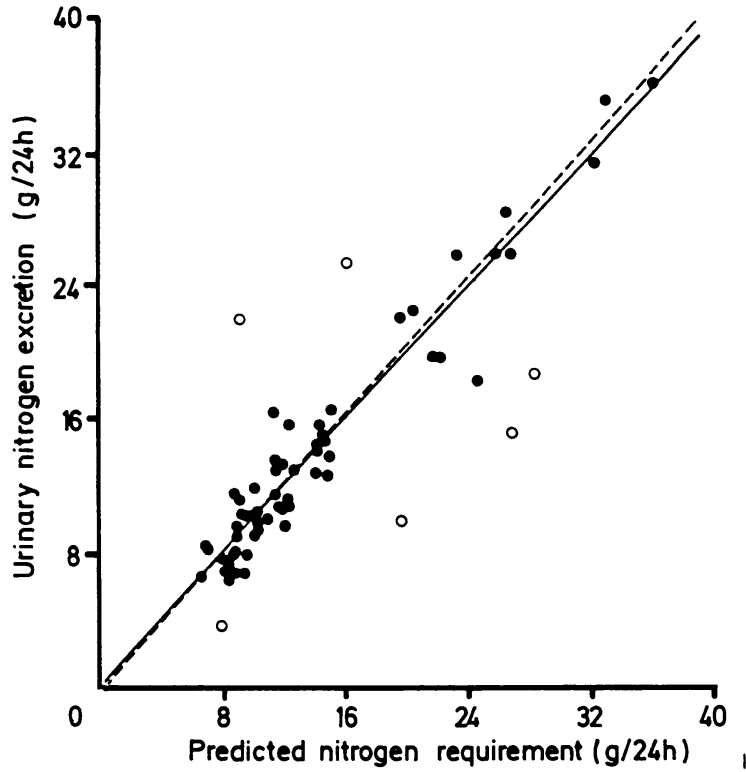

FIG 3-Comparison of measurea resting energy expenditures with predicted values. Solid line is least squares regression line. Broken line is line of identity.

Conversion: SI to traditional units-Energy: $1 \mathrm{MJ} \approx 239 \mathrm{kcal}$.

Figure 4 shows the weight chart of a woman aged 67 who had had a total gastrectomy followed by abdominal sepsis. Towards the end of the period of feeding oral intake was reintroduced as parenteral feeding was stopped. Despite a protracted and complicated clinical course, with no food taken orally for four months, her weight remained almost constant. Similar results were obtained in other patients. 

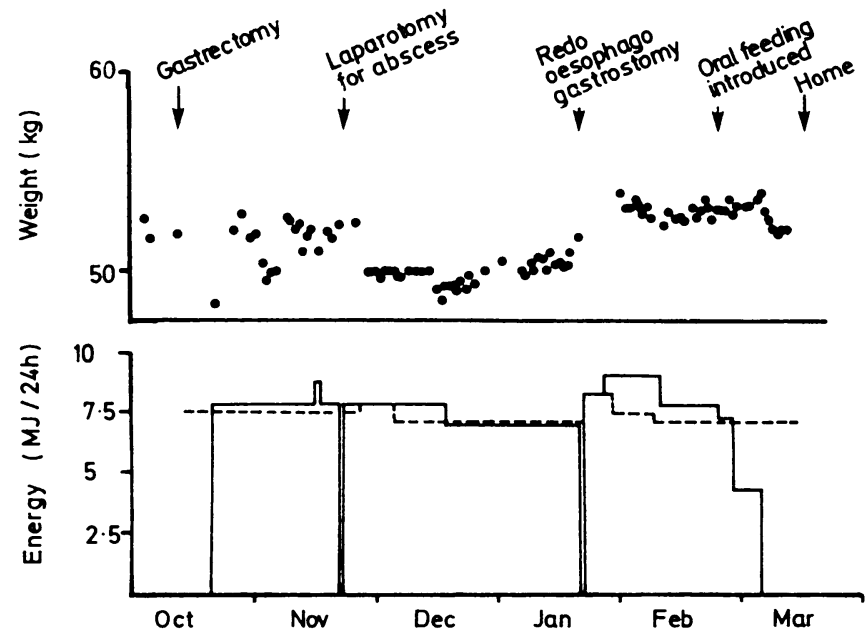

FIG 4-Weight chart of woman aged 67. Broken line shows energy requirement predicted by computer program. Solid line shows energy supplied as total parenteral nutrition.

Conversion: SI to traditional units-Energy: $1 \mathrm{MJ} \approx 239 \mathrm{kcal}$.

\section{Discussion}

Although the values calculated by the computer program are based on data from published reports, we needed to evaluate the way in which the program used the data. This was done by comparing the values predicted by the computer for energy and nitrogen requirements with the actual energy expenditures and nitrogen excretions of the patients.

The measured resting energy requirement was on average 0.93 of that predicted. This was true for people in all states, from those fully fit to those with severe sepsis. The calculation of basal energy expenditure may have been the common fault. Our results are consistent with the findings of Hill and Church, ${ }^{18}$ who found that measured resting energy expenditures of patients before and after surgery were $85-90 \%$ of those predicted, if the predicted value was taken as the basal metabolic rate plus $10 \%$. Little and Stoner have also found resting energy expenditure to be roughly $90 \%$ of that predicted ( $R$ A Little, personal communication). Perhaps new tables of the basal metabolic rate are now required.

Few patients had an energy requirement over 10.5 MJ (2500 $\mathrm{kcal}) / \mathrm{day}$, though the group studied did not include any patients with burns, who may well have much higher energy expenditures. ${ }^{12}$ This is in contrast with previously published work suggesting a requirement of $16 \cdot 7-25 \cdot 0 \mathrm{MJ}(4000-6000 \mathrm{kcal}) /$ day for critically ill patients receiving parenteral nutrition ${ }^{1920}$ but in agreement with more recent studies. ${ }^{67}$

From the results shown in table II it can be seen that the recommended daily intakes of energys are inappropriate for patients in hospital. The predictions of the program, having been calculated for each patient, were much closer than the recommended daily intake to the measured resting energy expenditures. Although the predictions of the program were on average $7 \%$ greater than measured values, it is unlikely that this small excess would seriously compromise the condition of the patient. In addition, each person is different, and the predictions of the program can only be a best estimate. This was seen in the variation about the regression line in figure 2 . The only way to be sure of a patient's energy expenditure is to measure it.

Although it was not possible to measure energy expenditure in ambulant subjects, many of the patients under the care of the clinical nutrition team were bedbound, and in these the measured recommended energy expenditure provided a good estimate of their total energy requirement. To allow for physical activity the data of Kinney et $a l^{11}$ were used without verification.

Nitrogen excretion in normal people increases with increasing nitrogen intake. The patients were, in most cases, given the amount of nitrogen prescribed by the program, which could account for the correspondence between predicted and measured nitrogen requirement. Measured nitrogen excretions in some extremely ill patients were, however, up to $35 \mathrm{~g} /$ day. In some of these patients, although the program predicted a similarly high requirement, only $17 \mathrm{~g} /$ day could be given because of volume restrictions. In addition, some patients with severe sepsis had high nitrogen excretions corresponding to those predicted by the program in the absence of any nitrogen intake. The good correspondence between predicted and measured excretions in these cases cannot be attributed to excretion of the amount supplied but must reflect the accuracy of the predictions made by the program.

No measurements were made of faecal or other nitrogen losses. If these were added to the measured urinary losses the gradient of the regression line would be further increased. It appears, therefore, that the ratios of energy to nitrogen used in the program may not predict sufficient nitrogen. This is despite the fact that they are much lower than the ratio of $1 \mathrm{~g}$ nitrogen $/ 1 \mathrm{MJ}(250 \mathrm{kcal})$ used in the tables of recommended daily intakes ${ }^{5}$ and also lower than in other published reports. ${ }^{12}$ Further studies are required to establish the appropriate ratios for groups of patients in hospital. Patients with hepatorenal failure excreted less nitrogen in the urine than predicted by the program. The routine to calculate the production of urea nitrogen was added to the program in order to assess nitrogen requirements for these patients and other patients with impaired renal function.

The nitrogen excretions of patients with teratoma or leukaemia correlated well with the predictions of the program during periods when no treatment was being administered. In some patients receiving chemotherapy, however, nitrogen excretion increased noticeably-for example, from 12 to $25 \mathrm{~g} /$ day-and it was necessary to determine requirements by monitoring the nitrogen balance as individual variation in response to chemotherapy made it difficult to produce a suitable computer prediction.

The program has proved extremely useful in the work of the clinical nutrition team at this hospital. Over 100 patients have been maintained on parenteral or enteral nutrition with regimens based on the predictions of the computer program, and good results have been obtained in all, without weight loss or with gradual weight gain as required. The program is used primarily to predict the energy and nitrogen requirements of patients under the care of the team. Losses of sodium, potassium, and water are greatly influenced by input, so it is difficult to predict the requirements of these. The predictions are therefore used as a starting point for treatment and are modified in the light of the patient's clinical condition, serum electrolyte concentrations, and balance data for water, electrolytes, and nitrogen. It seems unlikely that it will be possible to improve the predictions of water and electrolyte requirements because of the wide degree of variation between subjects.

Savings have been made in the cost of parenteral feeding as a result of the provision of regimens calculated for each patient. In the case of the patient whose details are shown in figure 4, $\$ 800$ was saved over four months compared with the estimated cost of a "standard" regimen giving $12.6 \mathrm{MJ}(3000 \mathrm{kcal})$ and $14 \mathrm{~g}$ nitrogen daily, ${ }^{21}$ with energy provided two thirds as carbohydrate and one third as lipid.

The use of a pocket computer has made possible individual and appropriate prescription of nutritional regimens for patients requiring intensive nutritional support by alleviating many problems previously associated with this. There is no need to carry large sheaves of tables on ward rounds, and errors of calculation are obviated. The calculations can be performed and the patient's feeding regimen decided on during the nutrition ward round or at any other convenient time and place. In addition, much time is saved in calculation, which helps to lighten the workload of the clinicians and dietitians. The program may also be used in circumstances in which nutritional knowledge is limited. It is part of a series of programs, including dietary assessment programs and the prescribing of enteral feeds, that will be published in the near future. The development of software for small, cheap computers represents a major advance in intensive nutritional support. 
We thank Sharp Electronics (UK) Ltd for the loan of the PC-1500 computer and Cow and Gate Ltd for the PC-1251. Also Professor A Guz and the department of medicine, Charing Cross Hospital Medical School, for the use of their equipment for measuring metabolic rates and Miss Janice Cam for performing many of the measurements. Several measurements of resting energy expenditure were performed at the Medical Research Council trauma unit, University of Manchester, and Hope Hospital, Salford, for which we thank Professor H B Stoner and Dr R A Little. Finally, we thank the other members of the clinical nutrition team at Charing Cross Hospital for their continuing support.

The programme may be obtained from CMC on cassette for the Sharp PC- 1500 or on microcassette for the PC-1251 for a modest handling charge. A program listing is also available. A version will shortly be available to run on the $\mathrm{BBC}$ microcomputer.

\section{References}

1 Sheldon GF, Petersen SR, Sanders R. Hepatic dysfunction during hyperalimentation. Arch Surg 1978;113:504-8.

2 Kirkpatrick JR, Dahn M, Lewis L. Selective versus standard hyperalimentation. Am $\mathcal{f}$ Surg 1981;141:116-21.

3 Askanazi J, Rosenbaum SH, Hyman AI, Silverberg PA, Milic-Emili J, Kinney JM. Respiratory changes induced by large glucose loads of total parenteral nutrition. JAMA 1980;243:1444-7.

4 Askanazi J, Nordenstrom J, Rosenbaum SH, et al. Nutrition for the patient with respiratory failure. Anesthesiology 1981;54:373-7.

5 Department of Health and Social Security. Recommended daily amounts of food energy and nutrients for groups of people in the United Kingdom. London: HMSO, 1977.
6 Quebbeman EJ, Ausman RK, Schneider TC. A re-evaluation of energy expenditure during parenteral nutrition. Ann Surg 1982;195:282-6.

Mcfie J. Energy requirements of surgical patients during intravenous nutrition. Ann $R$ Coll Surg Engl 1984;66:39-42.

Rich AJ, Wright PD. A pocket calculator program for intravenous requirements. Br $\mathcal{J}$ Surg 1980;67:313-4.

9 Robertson JD, Reid DD. Standards for basal metabolism of normal people in Britain. Lancet 1952;i:940-3.

10 Dubois D, Dubois EF. The measurement of surface area in man. Arch Intern Medicine 1916;17:863-71.

11 Kinney JM, Duke JH, Long CL, Gump FE. Tissue fuel and weight loss after injury. 7 Clin Pathol 1970;23(suppl 4):65-72.

12 Wilmore DW. The metabolic management of the critically ill. London: Plenum Medical, 1977: $1-50$.

13 Kielanowski J. Energy cost of protein deposition. In: Cole DJA, Boorman KN, Buttery PJ, Lewis D, Neale RJ, Swan H, eds. Protein metabolism and nutrition. London: Butterworths, 1976:207-15.

14 Woolfson AMJ. Metabolic considerations in nutritional support. In: Johnston IDA, Lee HA, eds. Developments in clinical nutrition. Tunbridge Wells: MSC Consultants, 1979:35-47.

15 Kopple JD. Nutritional therapy in renal failure. Nutr Rev 1981;39:193-206.

16 Shenkin A, Wretlind A. Parenteral nutrition. World Rev Nutr Diet 1978;28:1-111.

17 Diem K, Lentner C, eds. Scientific tables. 7th ed. Macclesfield: Geigy Pharmaceuticals, 1977:647-56.

18 Hill GL, Church J. Energy and protein requirements of general surgical patients requiring intravenous nutrition. Br $\mathcal{F}$ Surg 1984;71:1-9.

19 Kinney JM. Energy requirements of the surgical patient. In: Ballinger WF, Collins JA, Drucker WR, Dudrick SJ, Zeppa R, eds. Manual of surgical nutrition. Philadelphia: W B Saunders, 1975:223-5.

20 Spanier AH, Shizgal HM. Caloric requirements of the critically ill patient receiving intravenous hyperalimentation. Am $\mathcal{F}$ Surg 1977;133:99-104.

21 Squires JEA, Sim AJW, Garden OJ, et al. Nutritional audit-experience of a surgical nutritional advisory group. Proceedings of the Nutrition Society. Cambridge: Cambridge University Press, 1984;43:119A

(Accepted 8 January 1985)
GOURA KUital, Glasgow G20 9NB

DANIEL REID, MD, FRCP, director, Communicable Diseases Unit (Scotland)

G E D URQUHART, MB, FRCPATH, consultant virologist, regional virus laboratory

Woodside Health Centre, Glasgow G20 7LR

ERNEST T ROBINSON, FRCGP, general practitioner

Greater Glasgow Health Board, Glasgow G2

W DEREK WILSON, MB, MFCM, community medicine suecialist

T SCOTT WILSON, MD, FFCM, community medicine specialis

IAIN M STEWART, MB, MFCM, community medicine specialist

A T CAMPBELL, MB, MFCM, community medicine specialist

WILLIAM THOMSON, MB, MFCM, community medicine specialist

M SILVER, MB, MFCM, community medicine specialist

Correspondence to: Dr G Kudesia. primary response, and would differentiate those women who were protected by the vaccine from those with antibody to wild virus.

\section{Introduction}

The purpose of the rubella vaccination programme in schools is to ensure that all women are immune to rubella before they reach childbearing age. Some recent studies have failed to show an appreciable reduction in the numbers of susceptible women in the reproductive age group..$^{1.3}$ As two fifths of the babies damaged by rubella are firstborn children ${ }^{4}$ it is too late to establish the immune state of the mother at the first antenatal visit. We therefore conducted this study to determine the feasibility of a rubella vaccination programme based on the assessment of the immune state of schoolgirls, follow up vaccination, and checks of the immune state of those vaccinated.

\section{Subjects and methods}

Two schools in north west Glasgow were chosen for the study, the protocol of which was approved by the local ethical committee. The study sample consisted of 191 girls aged 11-13 who were due to be vaccinated in 1983. Written informed consent was obtained from the parents of the 128 